\title{
Technology Roadmapping for Renewable Fuels: Case of Biobutanol in Brazil
}

\author{
Julio Natalense', Désirée Zouain²
}

\begin{abstract}
Technology roadmapping has been used to define long term strategies and research agenda for the development of biofuels. The present work proposes the use of technology roadmapping as a technique for long term strategic planning of the biobutanol development, aligning long term goals with the resources, funding, and priorities to fulfill the needs in the development process in Brazil. Interviews have been used in the roadmapping process as an alternative to the workshops on market, product and technology. It allows the participation of companies in a highly competitive environment. The use of interviews allows the information to be collected individually, contributing to the elaboration of a roadmap. The results show that sugar cane has the potential to be used as a feedstock in the biobutanol production process, enabling Brazil to become a key exporter to supply other countries. For the short future, biobutanol has the potential to be produced in Brazil to replace petro-butanol as a solvent in industrial applications and to build the export platform for the fuels market .
\end{abstract}

Keywords: biofuel, biobutanol, technology roadmap.

\footnotetext{
1,2 Instituto de Pesquisas Energéticas e Nucleares (IPEN), Universidade de São Paulo, Brazil. Av. Lineu Prestes, 2242 - Cidade Universitária - CEP 05508-000 - São Paulo - SP Brazil. 'Corresponding author, e-mail: jnatalense@gmail.com
} 


\section{Introduction}

Two examples of renewable fuels in use today are bioethanol and biodiesel. The research and industrial interest has grown on biobutanol, with improvements on the traditional Acetone-Butanol-Ethanol (ABE) fermentation process, on the development of new bacteria strains to improve yield, and separation techniques to isolate the solvent. Companies plan to introduce biobutanol in to replace or blend it with gasoline. However, its interest as biofuel in Brazil is still limited, since the infrastructure is already adapted to bioethanol and gasoline.

This work proposes the use of technology roadmapping as a technique for long term strategic planning of the biobutanol development in Brazil, aligning long term goals with the resources, funding, and priorities to fulfill the needs in the development process.

\section{Technology Roadmaps}

\section{I Historical Perspective}

The technology roadmapping process is a methodology to build the technology plan of a company, sector or country, in order to guarantee the technologies will be ready on time to fulfill products for future market needs. The process identifies gaps in market, product and technology intelligence, supporting the planning initiatives and facilitating the communication between technical and commercial functions (Phaal, 200 la).

Techhnology roadmapping is a technique widely used for long term strategic planning. It considers the alignment of markets, products and technologies over time (Loureiro, 2010). The methodology supports technological management and planning, being especially important to explore and communicate interactions among the resources, organizational goals and environmental changes (Phaal, 2004a).

Technology roadmapping is defined as a needs-driven technology planning process which helps to identify, select, and develop technology alternatives for meeting product needs, and recommend its usefulness in current increasingly competitive environment (Garcia 1997). Roadmaps can be developed using the market pull approach, in which customer requirements are studied, or in market push approach, exploring technological innovations which may result in new business opportunities (Phaal, 2009a).

Willyard and McClees (1987) described a methodology where the following aspects are studied: description of the opportunity, forecast of necessary technologies, positioning in terms of quality and technology, resource de- ployment, mapping of intellectual property, description of the product, positioning reports and final report with the technology roadmap. Albright and Kappel (2003) described a similar methodology, organized in sessions dedicated to study the market, product, technology, and the planning map. Those steps included the description of the company and its competitors.

\subsection{The Roadmapping process}

According to Phaal (200 la), the roadmapping process should be considered as a learning opportunity about a certain subject. The final document must allow the visualization of the markets along a period of time, the products necessary to fulfill the market needs, and the technologies necessary to create or develop these products. The process suggests the need to collect and analyze information, interacting with experts on the subject, to form the final strategy.

The roadmap creation can be conducted in a series of workshops: market workshop, product workshop, technology workshop and roadmap workshop. In the preparation phase, the scope of the project, the facilitator, the compromise from senior leadership, the timeline and resources for the process are defined. During the first workshop, the value chains of the business and market are identified. It is an opportunity to review the company strategies, aligned with the trends on the market. On the product workshop, there is a review of existing or developmental products, in correlation with their performance attributes and ranking impact. Technologies are evaluated during another specific workshop, including the evolution and progress they must achieve to satisfy the needs and trends of the market. The final workshop is dedicated to group the information and elaborate a time-dependent final map for the strategic planning of products, identifying the opportunities derived from the available technologies (Phaal 200 lb). In summary, this process allows the definition of the strategic planning (S-Plan) and, through the technology planning (T-Plan), be able to achieve the innovation or development of new products (Oliveira, 20I0).

\subsection{Application to bioenergy}

Governments started to use the language of technology roadmaps to inform and promote technological transitions. While the industry tend to focus on short term and technical progress, the public and national roadmaps usually consider longer term goals, that involve technical, social and political changes (McDowall, 20I2).

Japan has promoted roadmaps for building collaborative relationships between different sectors in academia, industry and government (Yasuaga, 2009). The Chinese Academy of Sciences applied the methodology to draw the 
technology path for developing the energy matrix to 2050 (Chen, 2010). The International Energy Agency prepared a series of roadmaps covering nineteen innovative energy technologies (IEA, 20I0).

An example of roadmap applied to clean energy was published by Daim (2012). France used roadmaps to set priorities for developing second generation biofuels. Thermochemical and biochemical conversion routes of lignocellulosic feedstocks were suggested to produce fuels in enough quantities to comply with European directive 2003/30/EC that sets the target of 10\% biofuel use by 2020 (ADEME, 2009).

Technology goals for the development of cellulosic ethanol were set in USA based on a series of workshops of biomass to biofuels. A joint research agenda was achieved after reviewing in details the current technology, and defining research programs with specific technology goals, science milestones, deployed along a technical strategy timeline (DOE, 2006). Technology roadmaps were used to study the role of biobutanol, among other products, as a biofuel from lignocellulosic biomass via fermentation routes or synthetized from syngas (NSF, 2008).

\subsection{Technology roadmaps for biofuels in Brazil}

Brazil has specific programs to integrate comprehensive research on sugarcane and other crops that can be used for ethanol and other biofuels, as well as other products from integrated biorefineries (FAPESP, 20I2). Different types of biomass are studied for production of energy, evaluating their potential in terms of technical, economic, social and environmental viability, as well as suggesting policies for its implementation (CENBIO, 20I2).

Sugar cane is responsible for a considerable share of the energy matrix in Brazil, being 30\% only in The State of São Paulo. Bioethanol is used as fuel in the country since 1975, and today is commercialized either in pure form or blended at $25 \%$ in gasoline (Goldemberg, 20l I). Strategic studies were conducted to guarantee the sustainability and leadership in bioethanol production (CGEE, 2009).

Technology roadmaps identified that conversion route from bioethanol to biobutanol is in research phase in the period 2010-2015, with successive milestones until its possible commercialization in large scale in 2026-2030 (CGEE, 20 I0). Braskem applied technology roadmaps to define its priorities in green chemistry. Given its promising characteristics as a fuel and chemical intermediate, biobutanol from fermentation routes is being intensely researched by several companies, and its initial commercialization is expected within the next 5 years (Coutinho, 20l I).

\section{Butanol}

\section{I Historical perspective}

The industrial production of butanol started around 1912 . The fermentation process, known as ABE (acetone-butanol-etanol), was employed to ferment carbohydrates using Clostridium acetobutylicum to give mainly acetone and n-butanol. This process has achieved the scale of large industrial fermentation process, second only to ethanol fermentation in volume of solvent produced. After a peak in 1950, however, the persistent problems with fermentation reliability and increasing prices of molesses caused a decline in production (Bohlmann, 2007). Synthetic processes were introduced as the growing petrochemical industry offered cost effective routes to petro-butanol.

Currently butanol is produced mainly using synthetic processes known as hydroformilation, or oxo-process. It involves the reaction of an oleofin such as propylene with carbon monoxide and hydrogen to produce an aldehyde. This process is adopted widely to produce isobutyraldehyde and n-butyraldehyde, that are converted later to isobutanol and n-butanol. (NEXANT, 2007).

Since the 1990's, with the increasing cost of oil, researchers started to investigate improvements in biobutanol production by $A B E$ fermentation, through genetic engineering, more productive fermentors and new recovery technologies. A new bacteria strain designated Clostridium beijerinckii BA I0I, demonstrated efficiency in the conversion of starch to acetone and butanol (Bohlmann, 2007). Processes were developed using gas stripping system for in situ product removal, along with the development of solvent-resistant microorganisms (Bohlmann and Bray, 2008).

\subsection{Butanol products, production and uses}

Butanol is a four carbon alcohol with four structural isomers: n-butanol, isobutanol, tert-butanol and sec-butanol. The world demand for n-butanol was 3,800,000 tons in 2010. Global demand for isobutanol was 400,000 tons. The n-butanol is used as a solvent for paints and coatings, or as a chemical intermediate for the production of other products, such as n-butyl acrylate, a key monomer for preparing polymers and emulsions for paints used in construction. Isobutanol can be used as solvent, plasticizers and isobutyl acetate for use as flavoring agent (Mascal, 20I2). The other alcohols, tert-butanol and sec-butanol, have lower consumption and are used mainly as solvents.

Butanol is produced today primarily by the petrochemical route using the oxo-process. Main global producers are Dow, BASF, Celanese, and Eastman, as well as Sasol in South 
Africa, and $\mathrm{KH}$ Neochem in Japan and Elekeiroz in Brazil (Nejame, 20I0).

The production of biobutanol by fermentation route worldwide in 2008 was about 100,000 tons, mainly in China and demonstration facilities in the USA (Chiao and Sun, 2007). There is also a producer in Brazil, Usina Paraíso.

\subsection{Technologies for producing biobutanol}

Biobutanol can potentially be prepared by different fermentation and thermochemical processes, but some of these proposed processes are in early development stage and are not commercial yet. When selecting a potential technology to produce biobutanol, some of the most important factors to consider include the type and availability of biomass, the microorganisms being used, the fermentation technique and type of reactor, and recovering technique used to isolate and purify the solvent (Ranjan, 20I2).

The primary process for producing biobutanol is still the $A B E$ fermentation. The three major disadvantages of the conventional $A B E$ fermentation are a) economic feasibility due the unavailability of cheap feedstocks.; b) the low yields, since butanol is toxic to the microorganisms at very low concentrations; and c) inefficient and expensive product recovery processes (Kumar, 2012).

Corn has been the traditional feedstock in the USA. The $A B E$ fermentation employs a variety of Clostridia to produce Acetone, Butanol and Ethanol (ABE), usually in the proportion of 3:6:I parts. The existing processes employ feedstocks that allow sugars containing 6-carbons to be fermented to butanol. Starches and whole grains can be processed and converted to sugars for later fermentation. A life-cycle assessment (LCA) indicated the net energy generated for biobutanol production via $A B E$ fermentation from corn was $6.53 \mathrm{MJ} / \mathrm{L}$, compared to only $0.40 \mathrm{MJ} / \mathrm{L}$ produced by the corresponding manufacture of bioethanol from corn. (Swana, 20II).

Recently, sugarcane has been studied as a suitable feedstock for economically feasible production of butanol compared to other raw materials. This is an abundant source of soluble carbohydrates, which is ready to use in fermentations (Vilella Filho, 20I I). The economics and engineering of an $A B E$ process from sugarcane juice in Brazil was modeled by Mansur (20I0), indicating the possibility to operate a profitable unit. Processes for producing biobutanol from cane molasses have also been evaluated (Van der Merwe, 2010). The major breakthrough in feedstock usage is expected with development of the hydrolysis processes to break cellulose and hemicellulose into fermentable sugars. The acid and enzymatic processes for hydrolysis are being intensely researched in order to allow the use of large amounts of non-food, lignocellulosic feedstocks. These materials include agricultural wastes, such as corn stover, switchgrass, wheat straw and sugar cane bagasse. (Kumar, 2012). Cellulose exists along with hemicelluloses and lignin in the plant cell wall. Therefore, cellulose must be hydrolyzed to hexoses, i.e., sugars with six carbons, allowing the fermentation of glucose to butanol. Hemicellulose is composed by pentoses, i.e., sugars with five carbons, requiring specific microorganisms to convert it to biofuels. The pretreatment of the lignocellulose material is required to separate hemicelluloses, lignin, and other components from the cellulose substrate (Foyle, 2007).

The manufacturing process to obtain biobutanol can be divided in two parts: (a) the fermentation, and (b) separation and purification of the solvent from the fermentation broth. The biggest challenge is to obtain microorganisms with high productivity and selectivity to produce butanol. However, butanol itself can be toxic to a large portion of the microorganisms employed so far. In order to overcome this barrier it is necessary to develop more resistant microorganisms, or techniques for the continuous removal of the butanol being generated in order to maintain its low levels in the fermentation broth. Due to the low yield of the process, a large amount of energy is necessary to remove the water and purify the butanol, ethanol and acetone generated (Mariano, 20I2).

In summary the main elements to be considered when developing fermentation and separation technologies are:

- Butanol toxicity to microorganisms in levels as low as I to $2 \%$

- Low productivity of the conventional microorganisms, in general around $12 \mathrm{~g} / \mathrm{L}$

- Low selectivity of the process, generating several other products along with butanol

- High amount of water to distillate, increasing separation costs and enlarging the footprint of distillation units.

\section{Butanol as a fuel}

Brazil has been using bioethanol as a fuel for several decades. In this aspect, all the infrastructure for distribution and the car engines are adapted for the use of this chemical. In other countries, however, that now start to introduce biofuels in their matrix, ethanol has properties that are not desired. Its affinity for water consumes energy for distillation and may compromise its distribution by pipelines. It can be corrosive to certain metals, in special aluminum, and evaporates fast. Butanol blends well with gasoline and diesel, has a higher energy content than ethanol, has low affinity for water and is compatible with existing gasoline engines, not requir- 
ing adaptations. In countries where gasoline and diesel are the predominant fuels, either n-butanol or isobutanol have properties that allow their use as biofuels (Nejame, 2010).

Biobutanol has attracted interest for use as fuel due to the need to develop second generation biofuels to comply with the regulatory requirements of distinct countries and potential markets. In the United States, the Renewable Fuel Standard (RSF), from 2004, determines the addition of biofuels to gasoline.The U.S. Energy Independence and Security Act (EISA), known also as RFS2, indicates a need for a volume of 136 billion liters for biofuels to be used per year in the country by 2022 . The current bioethanol production in the US is around 40 billion liters. The RFS2 determines the use of biofuels, but does not authorize conversion in the engines to facilitate the use.

The majority of the vehicles in the United States were designed to run with gasoline. These vehicles accept up to $10 \%$ ethanol (EIO). Concentrations higher than $10 \%$ can damage the engines. The Environmental Protection Agency (EPA) studies the regulation of a $15 \%$ mixture (EI5) for vehicles manufactured after 200I. However, even EI 5 would make possible the use of biofuels only till 2016. This point is called Blending Wall. Above this limit, it would be necessary to make modifications in the existing car fleet and distribution infrastructure to allow a larger use of bioethanol. In this context, biobutanol can be used without restrictions when added to gasoline. It is possible to add $24 \%$ of renewable butanol to gasoline and maintain the same performance (Carmann, 20I I).

There is an opportunity for biobutanol, either in the United States to supply the internal market, as well as in Brazil to build an export base to other countries. Many companies have started to develop technologies to improve the production process for biobutanol, like GEVO, Butamax (Dupont / BP), Cobalt Technologies, Green Biologics / Butyl Fuel, Tetravitae / Eastman, Butalco and Cathay, among others. (Nejame, 2010).

\section{Field Research}

The primary objective of the research phase was to interview players in the Brazilian market and collect information to draw one specific roadmap for positioning biobutanol as fuel in Brazil. The intention was to validate the previous data obtained on technical and public reports and papers.

The scope of the interview included questions covering primary drivers as market, product and technologies. The universe of the interview included key contacts in the following areas: a) four companies developing biobutanol in Brazil, b) four producers of synthetic butanol or users as chemical intermediate, $d$ ) four research institutes and universities on bioenergy.

Similarly to the individual workshops proposed by Phaal (200 lb), the interviews contributed with the opinions from experts and opinion leaders to build the understanding of the technology flow in the roadmap.

\section{I Result from the interviews: Market}

\section{Opportunities: Brazilian and external markets}

The long term opportunity for biobutanol in the international market is the possibility to introduce a renewable fuel to the energy matrix of a country. This product will be accepted in large scale when it reaches the same cost and comparable performance to options currently available, bioethanol and biodiesel, when added to gasoline or conventional petro diesel.

There is an existing capacity of biobutanol by the ABE process in China, in special with Cathay. Some demonstration plants were started by Gevo in the USA and Butamax in the UK. The company Usina Paraíso, in the State of Rio de Janeiro - Brazil, is considered one of the few companies with consistent production of $n$-butanol. The estimated production volume of 2,000 tons is considered low even for the local market in Brazil.

A short term opportunity exists for companies to start production of biobutanol and offer it to the chemical market. In this segment, companies will have the opportunity to offer solvents at a higher price level than the average for biofuels, competing with products obtained from the petrochemical route. This initial market will be a firm outlet for early adopters while building capacity to reach a larger biofuels demand. The commercial offering of butanol as biofuel is expected in a timeline from 5 to 10 years. During this phase, producers will be in demonstration and process optimization phases, producing initial quantities for the chemicals market.

Producing biobutanol in Brazil is a viable option due to the large availability of raw material at convenient cost, in special sugar cane. Biobutanol should not be adopted largely as a biofuel in the country since the entire infrastructure is already adapted to the production and use of bioethanol. The demand for butanol as solvent in Brazil is 50,000 tons annually. This consumption is expected to grow to 150,000 tons by $2015 / 2016$ with the growth in the architectural paint market, and startup of a new world-scale plant to produce acrylic acid and butyl acrylate, which uses butanol as a key raw material. 
Taking advantage of the large industrial base already existing to produce ethanol in Brazil, producers may add biobutanol as an aggregate chemical to diversify and bring revenue to the mill. It is important to maintain production costs comparable to the petrochemical route, since the local market does not pay a premium for a renewable material.

\section{Commercialization Strategies}

International companies participating in the biobutanol segment usually operate with the following commercialization strategies: (a) technology licensing, (b) joint ventures or (c) acquiring a mill for proprietary production. This same model is being proposed in different countries, being adapted according to the local needs and opportunities.

In Brazil, there is large availability of biomass. This is complemented by the on-going research to make possible the process to hydrolyze cellulose from sugar cane bagasse or agricultural waste, allowing a better use of raw material and reducing production costs.

With the development of new microorganisms, fermentation routes, fermentation and distillation technologies, and availability of raw material, the biological process is attracting attention again in Brazil. The first volumes of biobutanol produced will be sold to the chemicals market. If confirmed their manufacturing and financial viability, these processes will compete with the conventional petrochemical route. The fermentation route will then attract new producers to generate volume to supply the potential export biofuels market in a period of 5 to 10 years.

It is not anticipated that biobutanol will find use as a general use renewable fuel in Brazil. Companies interested on the development of biobutanol in Brazil have focus on exports. The internal market should be satisfied with the initial quantities of biobutanol produced. In this case, there is advantage for the ethanol mills to convert part of their production to butanol. Initially, n-butanol will be placed in a higher market price for chemicals. It is expected that the $n$-butanol price generates a better financial return then the sale of bioethanol or biobutanol as fuel.

\section{Main production centers}

Brazil and India are pointed out as two countries that will have importance on the biobutanol scenario, due to the large availability of biomass, in special sugarcane, and the existing infrastructure to produce ethanol. China is adding production capacity and investing in research. In the United States, production is usually based on the corn culture and has pressures due to the competition with the food supply chain. The differential there could be the development of dis- tillation processes and hydrolysis process to use corn stover and other agricultural waste.

The strategy in the US has been clearly towards the conversion of ethanol mills to butanol. Similarly, ethanol mills in Brazil are being offered the opportunity to integrate butanol to their product portfolio, either with total conversion or as a diversification strategy. The introduction of a new product may reduce exposure to seasonality and price variation of sugar and alcohol, improving revenue and financial returns of the mill.

The development of the hydrolysis process may benefit not only the use of biomass from sugar cane, but other sources of cellulose as well. Brazil is a world leader in the production of eucalyptus fiber for pulp and paper, due the high productivity of this wood in the country. It would be possible to integrate bio refineries to the existing pulp mills, using agricultural waste or even cultivated forests dedicated to the manufacture of biofuels.

\section{Regulation Aspects}

The results of the interviews suggest that the adoption of butanol as a fuel in Brazil is one subject not being explored largely today. For other countries that are now defining regulation on the use of biofuels, butanol may present advantages. However Brazil has made its option in 1975 with the adoption of ethanol. Today, the vast majority of vehicles sold in the country have engines allowing the use of gasoline, ethanol, and any proportion between the two. Brazilian gasoline itself has an ethanol content of 22 to $25 \%$. All the distribution infrastructure and gas stations are already adapted to the use of this fuel. One specific opportunity for butanol in Brazil resides on its use as a possible component of blends with petrodiesel or biodiesel. Brazil is a net importer of diesel, and ethanol cannot be used due to its limited solubility in diesel.

A virtual adoption of butanol as a fuel in Brazil, due to its scale, would require synchronism between government and industry, in a coordinated effort or national plan that does not exist today. Obtaining approval from the National Oil Agency (ANP) is a required step to regulate the use. There is not information about existing studies to evaluate the environmental impact of engines using butanol.

\subsection{Result from the interviews: Product}

\section{Products in development}

Biobutanol is a generic term to designate any of the isomers obtained by the fermentation route. Depending on the type of microorganism employed, it is possible to produce n-bu- 
tanol or isobutanol. The traditional $A B E$ process generates $\mathrm{n}$-butanol and this is the product of interest today in Brazil. The domestic consumption is around 50,000 tons per year. Current production via petrochemical route reaches 20,000 tons per year from Elekeiroz, the only national producer, using the oxo process. The remaining volume is imported by companies such as Dow, BASF, Celanese and Eastman.

Current companies developing biobutanol intend to use bacteria to obtain $\mathrm{n}$-butanol or yeasts to obtain isobutanol. It is important to find outlets for these chemicals as well in order to optimize revenues. No company has yet made announcements to produce isobutanol in Brazil.

\section{Production Routes}

One of the points mentioned during the interviews is that, in fact, a "biobutanol" does not exist yet. Even though technically the production route and methods are known, regular processes will only have financial viability after optimization and validation of the research paths underway. Some of the companies exploring the commercial research on biobutanol are biotechnology startup who attracted venture capital for their initial operation. Some of the most promising companies have been acquired or joined forces with large and traditional multinationals. The production of biobutanol as solvent is expected in a short term, from I to 5 years. However the technology will be mature for the large adoption as a biofuel only within 10 to 15 years.

\subsection{Result from the interviews:Technologies}

\section{Implementation of biobutanol in Brazil}

Companies developing technology in biobutanol are primarily biotechnology companies, some of them startups with opportunistic capital or spin offs from academic research. There has been intense market activity to merge companies or acquisitions from larger companies.

Even though they have not yet announced local production plans for isobutanol, the company Butamax, a joint venture of BP and DuPont, has a development laboratory in the city of Paulínia, State of São Paulo, connected to a network of 150 professionals globally. There is expectation to export 7.6 billion liters of isobutanol from Brazil till 2020. This is approximately twice the total global production of butanol in 2012 .

Green Biologics has merged with Butyl Fuel, combining their knowledge base in optimizing microorganisms with the knowledge in process optimization from Butyl Fuel in the North-American market. The company differentiates the technology package offered to producers in each country, depending on the raw materials and microorganisms adequate for each region. Their technology is based on Clostridia and classified as an improved ABE process.

Cobalt Technologies announced in August 2012 their partnership with RHODIA to build a demonstration facility in Brazil till 2015 using sugarcane bagasse. Bunge joined the project as a strategic investor with intention to adopt the process in their sugarcane mills. The commercial operation of new butanol facilities in Brazil is expected for the period of 2 to 5 years.

\section{Feedstocks of interest in Brazil}

Sugar cane has been studied as a raw material for the production of butanol. It contains soluble carbohydrates, which can be converted readily by fermentation. The economic and engineering aspects of $A B E$ process based sugarcane have been modeled already, indicating the possibility of a profitable operation. Processes based on molasses have been modeled as well.

One of the main barriers for the use of sugarcane for chemicals is the competition with the price of sugar in the international market, as well as for the production of ethanol. The productivity of current processes for butanol is considered very low when using the sugar cane juice as the raw material for fermentation.

One of the main trends globally on biofuels is the development of hydrolysis processes for cellulose, allowing the conversion of lignocellulose material such as sugar cane bagasse and leaves or other biomass from agricultural waste. Nowadays the bagasse is burn for the generation of electric energy integrated with the sugar cane mills. The production of sugarcane in Brazil suffers from seasonality, being harvested in only 32 weeks per year. Some mills are introducing other sources of sugars, like sweet sorghum, during the nonproductive months of sugar cane.

The technical developments necessary for the biobutanol introduction are:

- Development of microorganisms capable of processing sugars with either five carbons or six carbons, which are generated from the hydrolysis of biomass;

- Reduction of the residence time for microorganisms to generate butanol, allowing a productivity increase and reduction of the size of new installations;

- Increased selectivity to convert sugars in butanol, and less ethanol, acetone and other by-products;

- Management of contaminations with foreign microorganism, and aseptic conditions to maintain the pure strains for the generation of the desired solvents. The sterilization of 
the system is an expensive operation for the mill, consuming steam and time, and increasing the cost of the equipment. - Development of microorganisms with higher tolerance to butanol, overcoming the barrier of $2 \%$ concentration (for ethanol, this value is around 12 to $13 \%$ );

- Development of processes to remove and purify the solvent reducing the distillation costs to process a large amount of water.

\section{Incentive to Research in Brazil}

In the field of incentives to research, there is a common initiative from BNDES (National Bank for the Economic and Social Development) and FINEP (Financing of Projects and Studies) to create the PAISS program (Joint Plan for the Incentive of Industrial Technological Innovation for Energy and Chemicals in the Sugar Sector). This program has been created specifically to subsidize research on cellulosic ethanol. The program includes three main development lines (FINEP, 2012). Butanol companies have benefited from financing in the line 2), as below:
- I) Second generation bioethanol

- 2) New products from sugarcane

- 3) Gasification of biomass: technologies, equipment, processes and catalysts

\section{Technology Roadmap for Biobutanol in Brazil}

The interaction with different companies and research institutes during the field research was important to validate information obtained during the literature review, as well as to integrate new knowledge to the research. The survey was designed with the objective to cover the main points proposed by Phaal (200 lb): market, product, technology. Different from seminars, in this mode the participants were interviewed individually, making comments about their opinions and information, without access to the information discussed by the remaining participants.

The roadmap was elaborated continuously during the literature review and interviews, being adjusted as new infor-

\section{Technology Roadmap for Biobutanol in Brazil 2013}

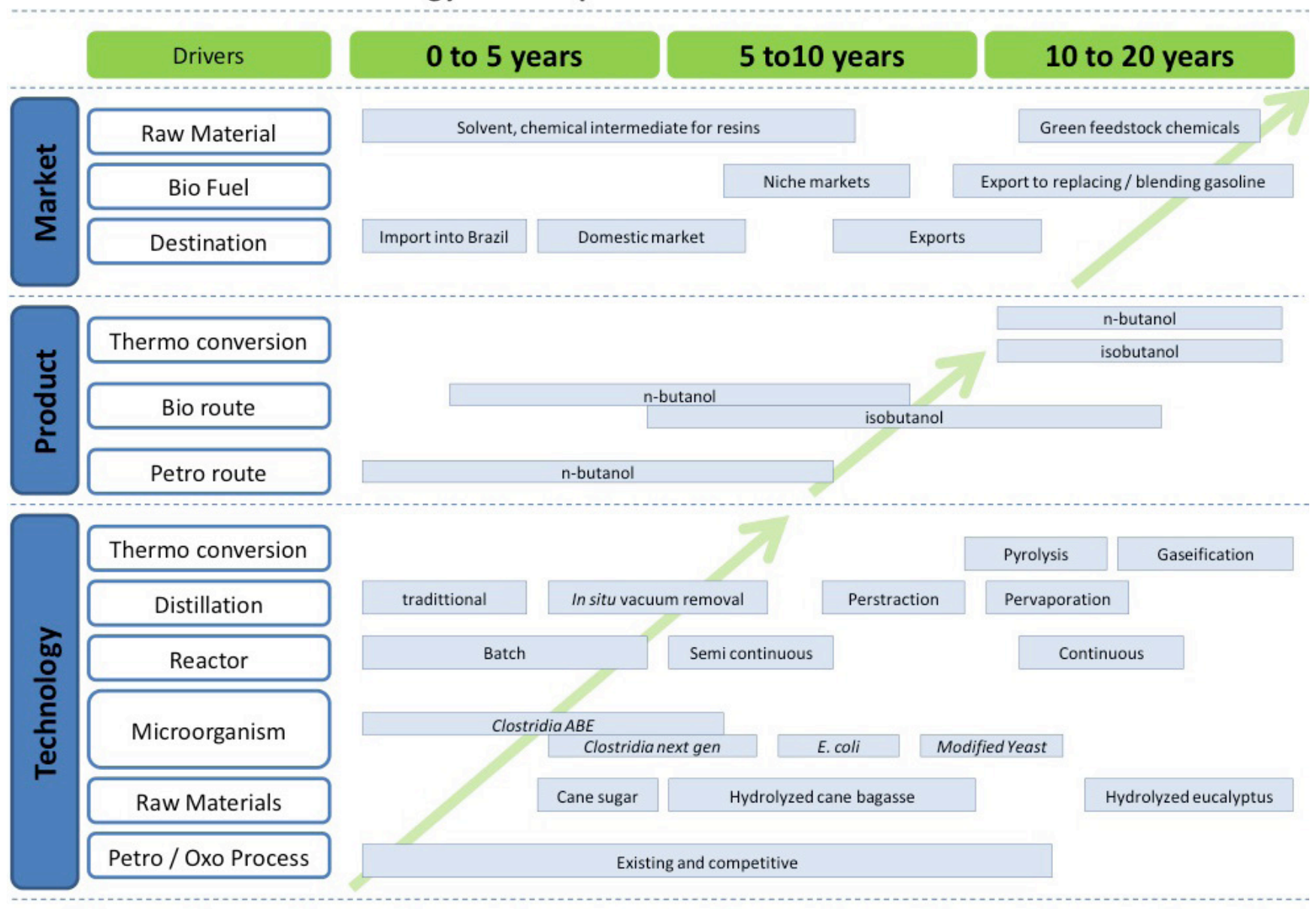

Figure I:Technology Roadmap for Biobutanol in Brazil 2013.

ISSN: 07 I8-2724. (http://www.jotmi.org)

Journal of Technology Management \& Innovation (C) Universidad Alberto Hurtado, Facultad de Economía y Negocios. 
mation or relation between the information became available. Figure I brings the architecture and information on the roadmap generated.

\section{Conclusions}

Brazil is expected to convert from a net importer to an exporter of $n$-butanol with the adoption of the fermentative processes. The initial quantities will supply the domestic market for solvent and chemical intermediates, followed by the export to the international market for chemicals and niche markets for fuels. On a later phase, the product should be exported for large distribution as renewable biofuel.

The use of biobutanol as a fuel is not anticipated in Brazil in the short term due to the existing use of bioethanol. There is a need for regulation to allow the use of butanol in Brazil. As the strategy around butanol production involves the conversion of part or a totality of a production from an ethanol mill, it is necessary to consider the supply chain to avoid reduced availability of ethanol in Brazil.

Regarding the roadmapping technique, the use of interviews was a viable alternative to the seminars on market, product and technology - in special to validate information collected on a previous step of in-depth literature review. This mode allows the participation of companies in a highly competitive environment where participants dispute a strategic technological position. In this context, it would be difficult to obtain cooperation of the participants if present on the same physical environment as in the seminars. The benefit of a face to face workshop is that participants can learn and elaborate on the information generated by the group. The use of interviews allows the information to be collected individually, contributing to the elaboration of a roadmap.

\section{References}

ADEME - The French Agency for Environment and Energy Management, July 2009. Roadmap for Second-Generation Biofuels.

ALBRIGHT, R.E., Kappel, T.A., 2003. Technology roadmapping: roadmapping the corporation. Research Technology Management, v. 46, n2, p3 I-40.

BOHLMANN, G., May 2007. Biobutanol, Process Economic Program, review 2007-I, SRI Consulting.

BOHLMANN, G., Bray, R., Dec 2008. Biobutanol, Report n. 264, Process Economic Program, SRI Consulting.

CARMANN, T., 20II. Biobutanol: Profile of an advanced biofuel and its path to market, International Sugar Journal, Volume II 3: 940I00.

CENBIO - Brazilian Reference Center on Biomass, available from http://cenbio.iee.usp.br (Last Accessed: 15Jul20 I2).

CGEE - Center for Strategic Studies and Management, 2009. Química Verde no Brasil: 2010-2030, (in Portuguese)

CHEN, Y., 2010. Energy Science \& Technology in China: A Roadmap to 2050, Chinese Academy of Sciences, Springer, Beijing.

CHIAO, J., Sun, Z., 2007. History of the Acetone-ButanolEthanol Fermentation Industry in China: Development of Continuous Production Technology, J Mol Microbiol Biotechnol; 13:I2-14.

COUTINHO, P., Bomtempo, J.V., 20I I. Roadmap Tecnológico em Matérias Primas Renováveis: Uma Base para Construção de Políticas e Estratégias no Brasil, Quim. Nova,Vol. 34, n. 5, 910-916 (in Portuguese).

DAIM, T.U., Amer, M., Brenden, R., 20I2. Technology Roadmapping for wind energy: case of Pacific Northwest, Journal of Cleaner Production, 20, p. 27-37.

DOE - US Department of Energy, 2006. Breaking the Biological Barriers to Cellulosic Ethanol: A joint research agenda, DOE/SC-0095.

FAPESP - The State of São Paulo Research Foundation, BIOEN program, available from http://bioenfapesp.org, (Last Accessed: I5Jul20I2)

FINEP, available from http://www.finep.gov.br/pagina. asp?pag=25.II, (Last Accessed: I6Out20 I2).

ISSN: 07 I8-2724. (http://www.jotmi.org) 
FOYLE, T., Jenings, L., Mulcahy, P., 2007. Compositional analysis of lignocellulosic materials: evaluation of methods used for sugar analysis of waste paper and straw. Bioresource Technology, 98 (16), 3026-3036.

GARCIA, M.L.,Bray, O.H., Apr 1997. Fundamentals of Technology Roadmapping, SAND97-0665, Sandia National Laboratories.

GOLDEMBERG, J., Aug 20I I. An historical account of bioenergy production in Brazil, Ist Brazilian BioEnergy Science and Technology Conference, Campos do Jordão.

IEA - International Energy Agency, 2010. Technology Roadmap for Solar Photovoltaic Cell.

KUMAR, M., Goyal,Y., Sarkar, A., Gayen, K., 20 I0. Comparative economic assessment of $A B E$ fermentation based on cellulosic and non-cellulosic feedstocks. Applied Energy 93, pp. 193-204.

LOUREIRO, A. M. V., Borschiver, S., Coutinho, P. L. A., 2010. The Technology roadmapping Method and its Usage in Chemistry. J.Technol. Manag. Innov. Vol5, Issue3, I8I-191.

MANSUR, M., 2010. ABE fermentation of sugar cane in Brazil, Senior Design Reports, University of Pennsylvania.

MARIANO, A.P., Qureschi, N., Maciel Filho, R., Ezeji, T.C., 2012. Assessment of in situ butanol recovery by vacuum during acetone butanol etanol ( $A B E)$ fermentation. J. Chem. Technol. Biotechnol., 87: 334-340.

MASCAL, M., 2102. Chemicals from biobutanol:technologies and markets, Biofuels, Bioprod. Bioref. 6:483-493.

MCDOWAL,W., 2010. Technology Roadmaps for transition management: The case of hydrogen energy, Technological Forecasting and Social Change, 79, 530-542.

NEJAME, S., 20I0. Butanol as a Fuel - View from the field, Promotum, presentation to NREL, March I I th, 2010.

NEXANT, Jul 2007. Oxo Alcohols 06/07-8, Process Evaluation Research Planning.

NEXANT, Feb 2008. Biobutanol:The Next Big Biofuel, topical report from Nexant Chem Systems.

OLIVEIRA, M. G., Rozenfeld, H., 2010. Integrating technology roadmapping and portfolio management at the front-end of new product development. Technology Forecasting and Social Change, 77, I339-1354.
PHAAL, R., Farrick, C.J.P., and Probert, D.R., 200 I (a). Technology Roadmapping: linking technology resources to business objectives, UK, University of Cambridge, Department of Engineering.

PHAAL, R., Farrick, C.J.P., and Probert, D.R., 200I (b). Fast Start Technology Roadmapping, UK, University of Cambridge, Department of Engineering.

PHAAL, R., Farrukh, C.J.P., Probert, D.R., 2004 (a).Technology roadmapping: A planning framework for evolution and revolution. Technologcal Forecasting \& Social Change. 7I, p. 5-26.

PHAAL, R., Muller, G., 2009 (a) .An architectural framework for roadmapping: Towards visual strategy, Technological Forecasting and Social Change, 76, p. 39-49.

PHAAL, R., 2009 (b). Fast Start Technology Roadmapping, Seminário Technology roadmapping: Conceitos, Práticas e Perspectivas, Escola Politécnica da USP, 3I August 2009.

RANJAN, A., Moholkar, V.S., 20I0. Biobutanol: science, engineering, and economics Int. J. Energy Res. ; 36: 277-323.

SWANA, J.,Yang,Y., Behnam, M.,Thompson, R., 20I I.An anal$y$ sis of net energy production and feedstock availability for biobutanol and bioethanol. Bioresource Technology 102, pP. 2II2-2117.

VAN DER MERWE, A.B., 20I0. Evaluation of Different Process Designs for Biobutanol production from Sugarcane Molasses, Master Dissertaion, University of Stellenbosch, South Africa.

VILLELA FILHO, M., Araujo, C., Bonfá, A., Porto, W., $201 \mathrm{I}$. Chemistry Based on Renewable Raw Materials: Perspectives for a Sugar-Cane Based Biorefinery, Enzyme Research, Article ID 654596.

WILLYARD, H., McClees, W. , 1987. Motorola's technology roadmap process. Research Management, 30(5),

YASUNAGA, Y., Watanabe, M., Korenaga, M., 2009. Application of technology roadmaps to governmental innovation policy for promoting technology convergence. Technology Forecasting and Social Change, 76, n. I, 6I-79. 